\title{
ДЕКАРТОВА СИСТЕМА КООРДИНАТ ЯК ІНСТРУМЕНТ ПОЗИЦІОНУВАННЯ ОБ'ЄДНАНИХ ТЕРИТОРІАЛЬНИХ ГРОМАД УКРАЇНИ
}

\author{
DOI: $10.32620 /$ cher.2020.4.05
}

Постановка проблеми. Необхідність позиціонування об'єднаних територіальних громад (ОТГ) обумовлена їх великої кількості та відсутністю їх ідентифікації. Ефективне позиціонування ОТГ потребує розробки відповідного інструментарію задля використання переваг територій. Метою cтатmi $є$ висвітлення результатів використання декартової системи координат задля позиціонування ОТГ на в контексті їх сталого розвитку, прикладі ОТГ Луганської області. Об'єкт дослідження - ОТГ Луганської області. Методи, використані в дослідженні: системного, компаративного та графічний аналізу (декартової системи координат у просторі). Гіпотезою дослідження стало припущення, що в якості інструменту оцінювання позицій ОТГ в контексті їх сталого розвитку можна використовувати декартову систему координат. Виклад основного матеріалу: на основі оцінки сталого розвитку ОТГ Луганської області визначено їх позиції в декартовій системі координат за допомогою програмного забезпечення geogebra; для визначення найкращих позицій у ОТГ Луганського регіону запропоновано використання вектору збалансованого позиціонування; встановлено, що найбільш збалансоване позиціонування має Лозно-Олександрівська ОТГ. Оригінальність та практична значимість дослідження полягають у пропозиції використовувати декартову систему координат у просторі в якості інструменту оцінювання позицій ОТГ. Висновки та перспективи подальших досліджень. Для оцінки позицій ОТГ було використано середній бал їх сталого розвитку за трьома складовими (економікою, соціальною, екологічною). Результати позиціонування ОТГ Луганського регіону було розкрито за допомогою декартовой системи координат та програмного забезпечення geogebra. Позиції ОТГ Луганського регіону відбито в площинах XOZ, XYZ, XOY. Для визначення найкращих позицій у ОТГ Луганського регіону запропоновано використання вектору збалансованого позиціонування, який дозволив встановити, що найбільш збалансоване позиціонування має Лозно-Олександрівська ОТГ, яка знаходиться на векторі. Подальші дослідження мають бути спрямовані на визначення заходів задля здійснення збалансованого розвитку ОТГ.

\section{Ключові слова:}

інструмент, оцінка, позиціювання, об’єднана територіальна громада, декартова система координат, простір, вектор.

1 Заблодська Інна Володимирівна, д-р екон. наук, професор, Заслужений економіст України, завідувач відділу проблем міжрегіонального співробітництва, Державна установа «Інститут економікоправових досліджень імені В.К. Мамутова Національної академії наук України», м. Київ, Україна

Zablodska Inna, Doctor of Economic Sciences, Professor, Honored Economist of Ukraine, Head of the Department of Interregional Cooperation Problems, State Institution "V.K. Mamutov Institute of Economic and Legal Research National Academy of Sciences of Ukraine", Kyiv, Ukraine.

e-mail: zablodin@gmail.com

ORCID ID: 0000-0002-1410-6194

${ }^{2}$ Сєрєбряк Ксенія Ігорівна, д-р екон. наук, професор, професор кафедри економіки та підприємництва, Східноукраїнський національний університет ім. В. Даля, м. Сєвєродонецьк, Україна.

Sieriebriak Ksenia, Doctor of Economic Sciences, Professor, professor of the enterprise economy department Volodymyr Dahl East Ukrainian National University, Severodonetsk, Ukraine.

ORCID ID: 0000-0002-7025-2399

e-mail: ep.ti.vnu@gmail.com

${ }^{3}$ Бєлоусова Любов Іванівна, канд. екон. наук, доцент, доцент кафедри адміністративного управління, менеджменту та маркетингу, Східноукраїнський національний університет ім. В. Даля, м. Сєвєродонецьк, Україна.

Belousova Lubov, Ph.D. in Economics, associate professor of the management and marketing department, Volodymyr Dahl East Ukrainian National University, Severodonetsk, Ukraine.

ORCID ID: 0000-0002-5722-7463

e-mail: belousova_2014@ukr.net 


\section{CARTESIAN COORDINATE SYSTEM AS A POSITIONING TOOL OF AMALGAMATED TERRITOTIAL COMMUNITIES IN UKRAINE}

Problem statement. The need for positioning of amalgamated territorial communities (ATC) is due to their large number and lack of identification. Effective ATC positioning requires the development of appropriate tools to take advantage of the territory. The purpose of the article is to highlight the results of using the Cartesian system of coordination of the rear positioning of ATC in the context of their sustainable development, examples of ATC Luhansk region. The research object is ATC of Luhansk region. The methods used in the reaserch are: system, comparative and graphical analysis (the Cartesian coordinate system in space). The reaserch hypothesis was the preparation that the Cartesian coordinate system can be used as a tool for assessing the positions of ATCs in the context of their sustainable development. Presentation of the main material: on the basis of sustainable development estimates of ATC of Luhansk region their positions in the Cartesian coordinate system are determined with the help of geogebra software; to determine the best positions in the ATC of Luhansk region, it is proposed to use the vector of balanced positioning; it is established that the Lozno-Oleksandrivska ATC has the best balanced positioning.The originality and practical significance of the reaserch polarize the propositions of vicoristic Cartesian coordinate systems for the simplest tools for controlling the positions of ATC . Conclusions and prospects fot the further reaserches. For the assessment of ATC positions, it was used a middle ball of the development by three warehouse (economy, social, environmental). The result of the positioning of ATC of the Luhansk region was filled with a rosary behind an additional Cartesian coordinate system and software geogebra protection. The positions of ATC of the Luhansk region are displayed in the areas XOZ, XYZ, XOY. For setting the best positions at the ATC of the Luhansk region, the reference station is assigned to the vector of the balanced position, which dials up, for the most unbalanced positions from the Lozno-Oleksandrivska position. Subsequent reaserches may be directed to the value of visits for the purpose of the balanced development of ATC.

Keywords:

tool, estimation, positioning, amalgamated territorial community, Cartesian coordinate system, space, vector.

\section{ДЕКАРТОВА СИСТЕМА КООРДИНАТ КАК ИНСТРУМЕНТ ПОЗИЦИОНИРОВАНИЯ ОБЬЕДИНЕННЫХ ТЕРРИТОРИАЛЬНЫХ ОБЩЕСТВ УКРАИНЫ}

Постановка проблемы. Необходимость позиционирования объединенных территориальных общин (ОТГ) обусловлена их большого количества и отсутствием их идентификации. Эффективное позиционирование ОТГ требует разработки соответствующего инструментария для использования преимуществ территорий. Целью статьи является освещение результатов использования декартовой системы координат для позиционирования ОТГ на в контексте их устойчивого развития, примере ОТГ Луганской области. Объект исследования - ОТГ Луганской области. Memoдbl, ucnoльзованные в исследовании: системного, сравнительного и графический анализа (декартовой системы координат в пространстве). Гипотезой исследования стало предположение, что в качестве инструмента оценки позиций ОТГ в контексте их устойчивого развития можно использовать декартову систему координат. Изложение основного материала: на основе оценки устойчивого развития ОТГ Луганской области определены их позиции в декартовой системе координат с помощью программного обеспечения geogebra; для определения лучших позиций в ОТГ Луганского региона предложено использование вектора сбалансированного позиционирования; установлено, что наиболее сбалансированное позиционирования имеет Лозно-Александровская ОТГ. Оригинальность и практическая значимость исследования заключаются в предложении использовать декартову систему координат в пространстве в качестве инструмента оценки позиций ОТГ. Выводы и перспективы дальнейших исследований. Для оценки позиций ОТГ было использовано средний балл их устойчивого развития по трем составляющим (экономикой, социальной, экологической). Результаты позиционирования ОТГ Луганского региона было раскрыто с помощью декартовой системы координат и программного обеспечения geogebra. Позиции ОТГ Луганского региона отражено в плоскостях XOZ, XYZ, XOY. Для определения лучших позиций в ОТГ Луганского региона предложено использование вектора сбалансированного позиционирования, который позволил установить, что наиболее сбалансированное позиционирования имеет Лозно-Александровская ОТГ, которая находится на векторе. Дальнейшие исследования должны быть направлены на определение мер для осуществления сбалансированного развития ОТГ.

Ключевые слова:

инструмент, оценка, позиционирование, объединенная территориальная община, декартова система координат, пространство, вектор. 
Постановка проблеми. Розвиток процесів децентралізації влади в Україні передбачає створення об'єднаних територіальних громад (ОТГ), які мають позиціонуватися задля свого успішного розвитку. Позиціонування територій або ОТГ здійснюються задля визначення наявного або бажаного сприйняття суспільством (стейкхолдерами) їх переваг, які можуть бути досягнуті (розвинуті) за результатами реалізації стратегії розвитку ОТГ і за допомогою бренду та / або айдентики [1, с. 46].

Проблематика позиціонування території або ОТГ набуває актуальності та сучасності через потребу формування спроможних ОТГ не тільки за рахунок ефективного виробництва, а і за рахунок використання переваг територій - історичних, географічних, демографічних та інших.

Сучасний інструментарій позиціонування територій або ОТГ дуже великий, до яких, насамперед, відносять: імідж, бренд, ділову репутацію тощо. Проте існує необхідність розширення гами інструментів щодо оцінювання позицій ОТГ задля забезпечення їх сталого розвитку, що й обумовлює своєчасність та актуальність обраної тематики дослідження.

Аналіз останніх досліджень і публікацій. Дослідженню проблематики позиціонування територій присвятили свої праці такі вчені, як Ф. Котлер [2], Г. Карпентер [3], В. Доу, К. Лім, С. Чентінг [4]; А. Сундук [5], В. Течерунгрой, М. Мутута [6], І. Буднікевич [7], О. Коломицева [8], С. Пепчук [9] та інші. Віддаючи належне досить широкому колу наукових праць 3 обраної проблематики, необхідно зазначити, що більшість 3 них зосереджує свою увагу на теоретичних та практичних аспектах щодо позиціонування територій, проте питання пов'язані з позиціонування ОТГ набувають більшої актуальності.

Метою статті $є$ висвітлення результатів використання декартової системи координат задля позиціонування ОТГ на в контексті їх сталого розвитку, на прикладі ОТГ Луганської області.

Виклад основного матеріалу дослідження. У межах проведення наукових досліджень за відомчою тематикою «Іден- тифікація та позиціонування об'єднаних територіальних громад Луганської й Донецької областей» науковці Державної установи Інституту економіко-правових досліджень імені В.К. Мамутова НАН України провели кількісно-якісне оцінювання сталого розвитку об'єднаних територіальних громад Луганської області. Оцінювання проводилося за трьома складовими сталого розвитку.

Економічна складова сталого розвитку об'єднаних територіальних громад була оцінена за допомогою групи індикаторів:

забезпечення фінансової та бюджетної спроможності,

формування підприємницького потенціалу,

розвитку системи інженернотранспортної інфраструктури.

Соціальна складова сталого розвитку об'єднаних територіальних громад була оцінена за допомогою групи індикаторів:

розвитку системи соціальної інфраструктури та надання послуг населенню,

демографічного розвитку громади.

Екологічна складова сталого розвитку об'єднаних територіальних громад була оцінена за допомогою групи індикаторів:

використання природногеографічного та екологічний потенціалу,

використання унікальної історикокультурної спадщини в контексті підвищення туристично-рекреаційного потенціалу.

Середній бал за результатами оцінювання складових сталого розвитку об'єднаних територіальних громад Луганського регіону подано у таблиці 1.

Використовуючи отримані данні визначимо позиції ОТГ Луганського регіону в контексті їх сталого розвитку в декартовій системі координат у просторі за допомогою програмного забезпечення geogebra.

Декартова система координат у просторі $€$ трійкою попарно перпендикулярних осей (вісь $\mathrm{OX}$ - вісь абсцис, вісь ОУ - вісь ординат, вісь $\mathrm{OZ}$ - вісь аплікат), які мають спільний початок O (початок координат) i однаковий масштаб уздовж осей. 
Середній бал результатів оцінювання складових сталого розвитку об'сднаних територіальних громад Луганського регіону (станом на 01.01.2020 р.)

\begin{tabular}{|c|c|c|c|c|c|c|c|c|}
\hline \multirow[b]{2}{*}{ Складові } & \multicolumn{8}{|c|}{ ОТГ Луганської області } \\
\hline & 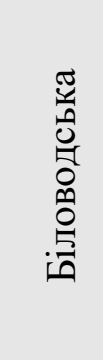 & 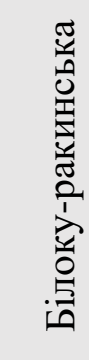 & 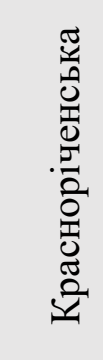 & 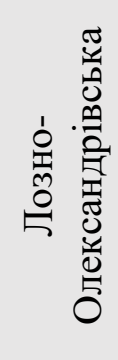 & 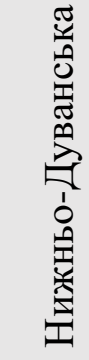 & 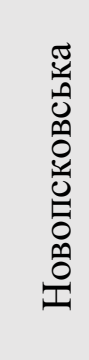 & 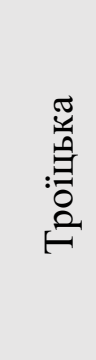 & 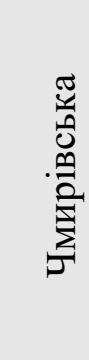 \\
\hline Умовні позначення & $\mathrm{G}$ & A & $\mathrm{B}$ & $\mathrm{D}$ & $\mathrm{E}$ & $\mathrm{N}$ & $\mathrm{T}$ & $\mathrm{F}$ \\
\hline Економічна складова (x) & 5,25 & 6,74 & 2,47 & 5,3 & 3,67 & 3,34 & 7,32 & 3,79 \\
\hline Соціальна складова (у) & 5,61 & 5,94 & 5,05 & 4,90 & 4,22 & 6,26 & 5,29 & 6,13 \\
\hline Екологічна складова (z) & 7,37 & 7,37 & 4,24 & 5,07 & 6,5 & 6,6 & 2,84 & 2,44 \\
\hline
\end{tabular}

Кожній точці простори за певним правилом ставиться у відповідність трійка чисел - абсциса, ордината та апліката (x; у; z), які називаються декартовими координатами точки. Ці координати визначаються в такий спосіб: через точку А проводиться три площини, паралельні координатним площинам YOZ, XOZ, XOY. Iз координатними осями OX, OY, OZ площини перетнуться в точках $\mathrm{x}_{\mathrm{A}}, \mathrm{y}_{\mathrm{A}}, \mathrm{z}_{\mathrm{A}}$. Для точок пло-

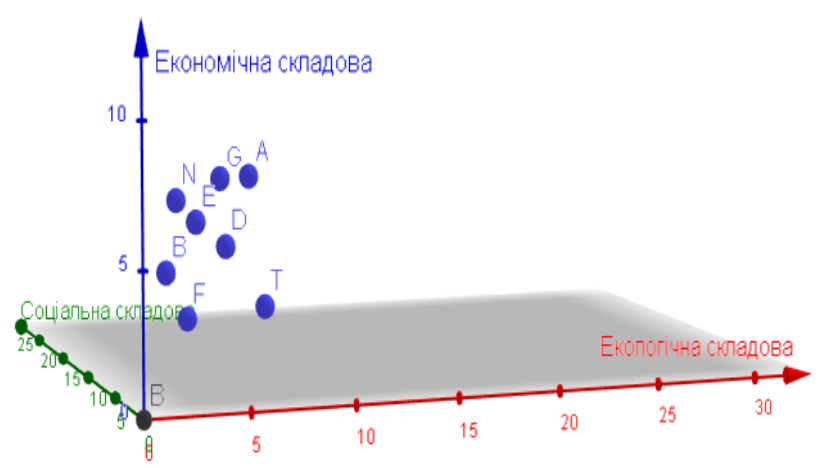

Рисунок 1 - Результати позиціонування об'єднаних територіальних громад Луганського регіону Джерело: розроблено авторами

На рис. 2, 3 і 4 подано результати позиціонування об'єднаних територіальних громад Луганського регіону в декартовій щини $\mathrm{XOY}$ апліката z дорівнює нулю, для точок площини XOZ - ордината у дорівнює нулю, для точок площини YOZ - абсциса х дорівнює нулю [10].

Отже, на рис. 1 подано результати позиціонування об'єднаних територіальних громад Луганського регіону в декартовій системі координат у просторі за допомогою програмного забезпечення geogebra. 


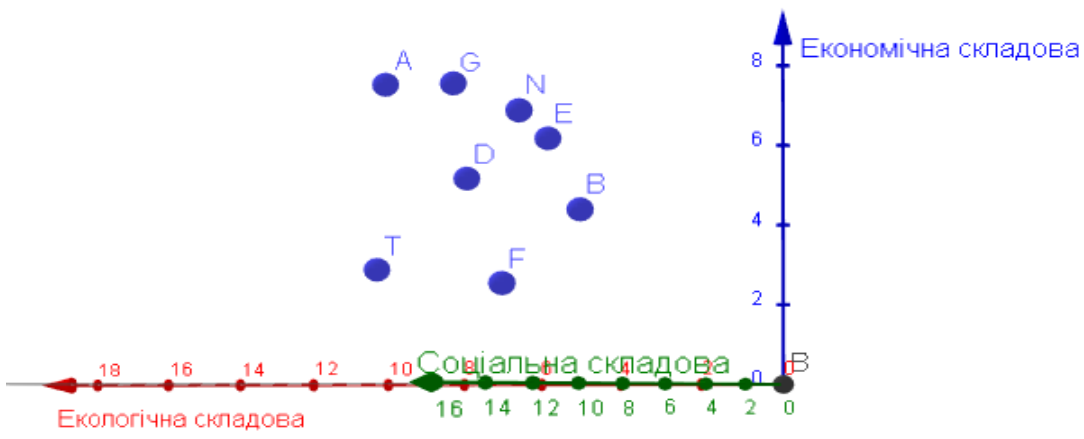

Рисунок 2 - Результати позиціонування об'єднаних територіальних громад Луганського регіону, площина XOZ Джерело: розроблено авторами

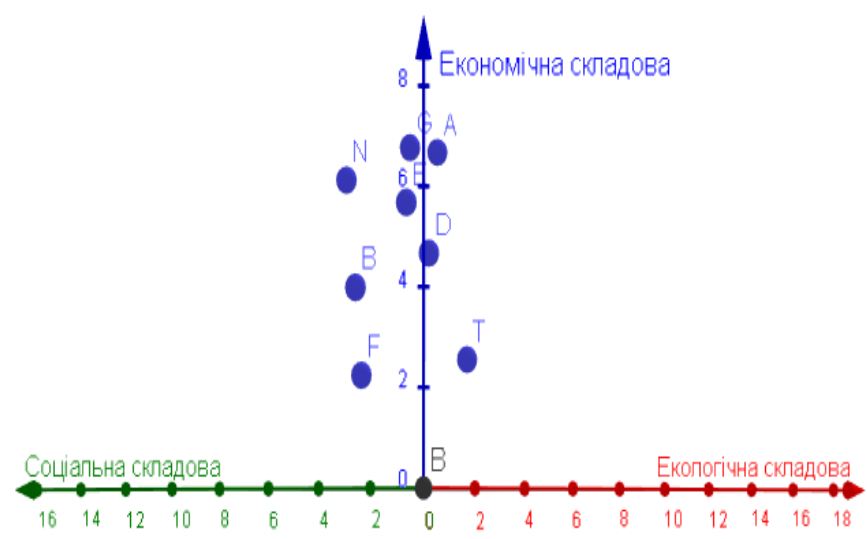

Рисунок 3 - Результати позиціонування об'єднаних територіальних громад Луганського регіону, площина XYZ

Джерело: розроблено авторами

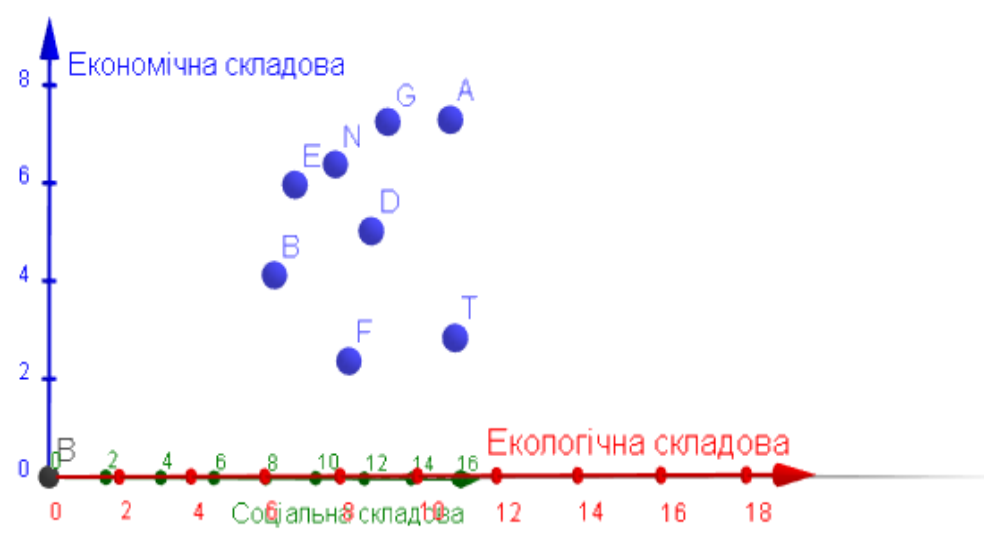

Рисунок 4 - Результати позиціонування об'єднаних територіальних громад Луганського регіону, площина XOY

Джерело: розроблено авторами

Проте для визначення найкращих позицій у об’єднаних територіальних громад Луганського регіону пропонується викори- стання вектору збалансованого позиціонування (ОС), рис. 5,6, 7 і 8. 


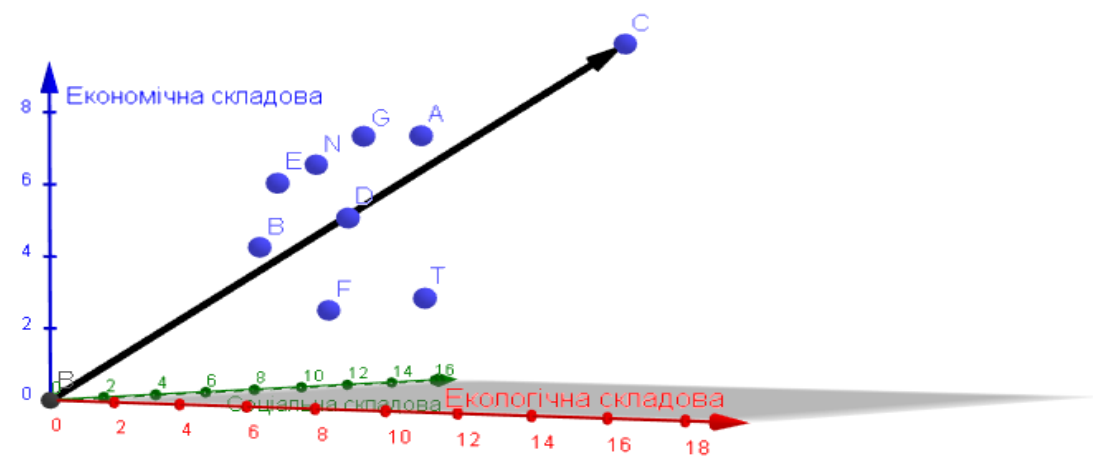

Рисунок 5 - Використання вектору збалансованого позиціонування задля оцінки сталого розвитку ОТГ Луганського регіону (вид 1) Джерело: розроблено авторами

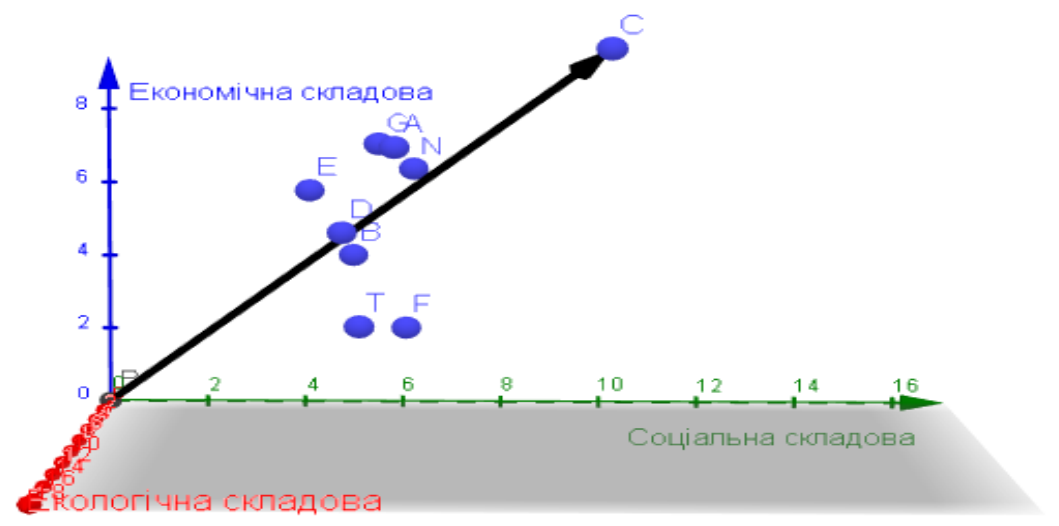

Рисунок 6 - Використання вектору збалансованого позиціонування задля оцінки сталого розвитку ОТГ Луганського регіону (вид 2) Джерело: розроблено авторами

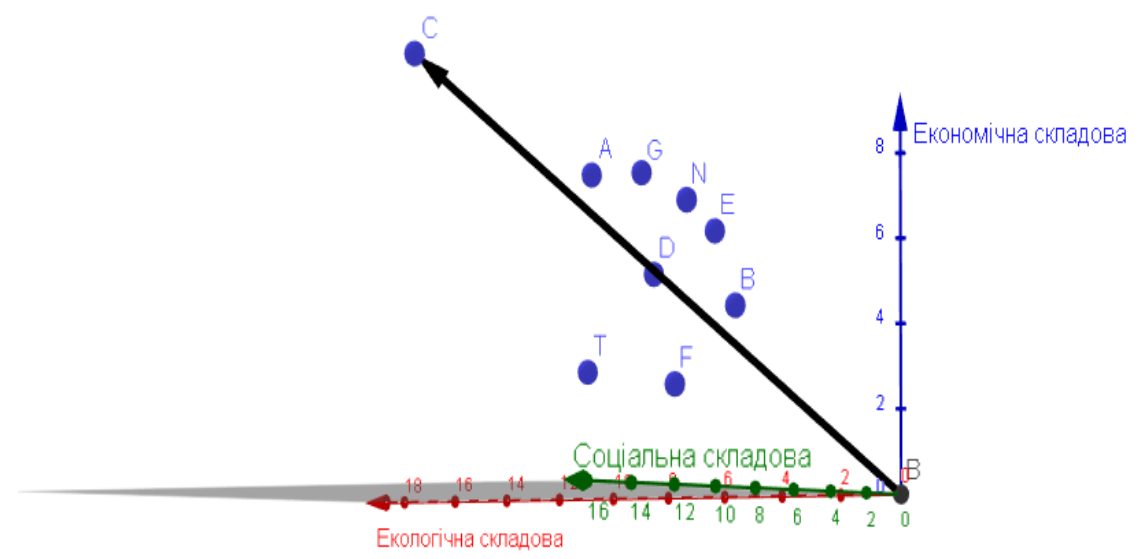

Рисунок 7 - Використання вектору збалансованого позиціонування задля оцінки сталого розвитку ОТГ Луганського регіону (вид 3) Джерело: розроблено авторами 


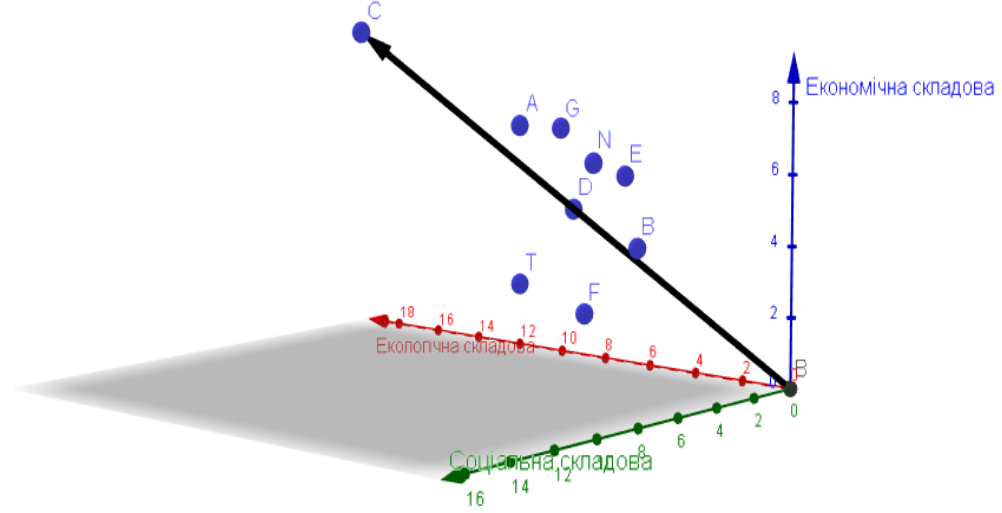

Рисунок 8 - Використання вектору збалансованого позиціонування задля оцінки сталого розвитку ОТГ Луганського регіону (вид 4) Джерело: розроблено авторами

Отже, використання вектору збалансованого позиціонування об'єднаних територіальних громад Луганського регіону дозволило встановити, що найбільш збалансоване позиціонування має ЛозноОлександрівська ОТГ (D), оскільки вона майже знаходиться на векторі ОС. Всі ОТГ мають відмінні позиції. Троїцька і Чмирівська ОТГ мають найгірші позиції, оскільки вони знаходяться під вектором збалансованого розвитку. Решта ОТГ мають найбільш вдалі позиції у контексті сталого розвитку.

Висновки та перспективи подальших досліджень. Для оцінки позицій ОТГ Луганської області було розраховано середній бал їх сталого розвитку за трьома складовими (економікою, соціальною, екологічною). Результати позиціонування ОТГ Луганського регіону було визначено в декартовій системі координат у простоpi за допомогою програмного забезпечення geogebra. Також результати позиціонування ОТГ Луганського регіону подано в площинах XOZ, XYZ, XOY. Для визначення найкращих позицій у об'єднаних територіальних громад Луганського регіону запропоновано використання вектору збалансованого позиціонування (OC), який дозволив дозволило встановити, що найбільш збалансоване позиціонування має Лозно-Олександрівська ОТГ (D), яка знаходиться на векторі ОC. Троїцька i Чмирівська ОТГ мають найгірші позиції, оскільки вони знаходяться під вектором збалансованого розвитку. Найбільш вдалі позиції у контексті сталого розвитку мають всі інші ОТГ .

\section{Література}

1. Устименко В. А., Заблодська І.В., Бурбело С.О., Заблодська Д.В., Саєнко П.О. Ідентифікація та позиціонування об'єднаних територіальних громад: методичний інструментарій. Економіка та право. 2019. № 1. C. 44-50.

2. Kotler P. Marketing's New Paradigm: What's Really happening Out There. Planning Review. 1992. Vol. 20 (5). P. 50-52.

3. Carpenter G. Perceptual position and competitive brand strategy in a twodimensional, 2-Brand market. Management Science. 1989. Vol. 35. No.9. P. 1029-1044. DOI: $10.1287 / \mathrm{mnsc} .35 .9 .1029$

4. Dou W., Lim K., Chenting S. Brand positioning strategy using search marketing. Mis Quarterly. 2010. Vol. 34. No.2. P. 261279.

5. Sunduk A.M. Positioning of Trans Carpathian region within the system "State Global dimension". Actual Problems of Economics. 2012. Vol. 128. P. 211-218.

6. Taecharungroj V., Muthuta M., Boonchaiyapruek P. Sustainability as a place brand position: a resident-centric analysis of the ten towns in the vicinity of Bangkok. Place Branding and Public Diplomacy. 2019. Vol. 15. No.4. P. 210-228.

7. Буднікевич I., Романюк Н. Маркетинговий підхід до побудови мережевих моделей на регіональному ринку знань. 
Збірник наукових пращь ЧДТУ. Серія: Економічні науки. 2019. Вип. 54. С. 52-59.

8. Kolomytseva O. Positioning of regions of Ukraine in competitive environment. Proceedings of the 1st International Conference Contemporary Issues in Theory and Practice of Management: CITPM 2016. Czestochawa, Poland (April 21-22, 2016). P. 203-209.

9. Пепчук С.М. Позиціонування регіону в системі конкурентних відносин: дис. на здобуття наук. ступеня канд. екон. наук : [спец.] 08.00.05 "Розвиток продуктивних сил і регіональна економіка" / Черкаський державний технологічний університет. Черкаси, 2016. 341 с.

10. Декартові координати у просторі. URL: ttp://zno.academia.in.ua/mod/ book/view.php?id=3217 (дата звернення 10.12.2020).

\section{Reference}

1. Ustimenko, V.A., Zablodskaya, I.V., Burbelo, S.O., Zablodskaya, D.V., Saenko, P.O. (2019) Identification and positioning of united territorial communities: methodological tools. Economics and law, 1, 44-50.

2. Kotler, P. (1992) Marketing's New Paradigm: What's Really happening Out There. Planning Review, 20 (5), 50-52.

3. Carpenter, G. (1089) Perceptual position and competitive brand strategy in a two-dimensional, 2-Brand market. Management Science, 35, 9, 1029-1044. DOI: 10.1287/mnsc.35.9.1029

Стаття надійшла

до редакції : 12.11.2020 p.
4. Dou, W., Lim, K. (2010) Chenting S. Brand positioning strategy using search marketing. Mis Quarterly, 34, 2, 261-279.

5. Sunduk, A. M. (2012) Positioning of Trans Carpathian region within the system "State - Global dimension". Actual Problems of Economics, 128, 211-218.

6. Taecharungroj, V., Muthuta, M., Boonchaiyapruek, P. (2019). Sustainability as a place brand position: a resident-centric analysis of the ten towns in the vicinity of Bangkok. Place Branding and Public Diplomacy, 15, 4, 210-228.

7. Budnikevich, I., Romanyuk, N. (2019). Marketingovij pidhid do pobudovi merezhevih modelej na regional'nomu rinku znan. Zbirnik naukovih prac' CHDTU. Seriya: Ekonomichni nauki, 54, 52-59.

8. Kolomytseva, O. Positioning of regions of Ukraine in competitive environment. Proceedings of the $1 s t$ International Conference Contemporary Issues in Theory and Practice of Management: CITPM 2016. Czestochawa, Poland (April 2122, 2016), 203-209.

9. Pepchuk, S. M. (2016). Pozicionuvannya regionu $v$ sistemi konkurentnih vidnosin: dis. na zdobuttya nauk. stupenya kand. ekon. nauk : [spec.] 08.00.05 "Rozvitok produktivnih sil i regional'na ekonomika" / CHerkas'kij derzhavnij tekhnologichnij universitet. CHerkasi, 341.

10. Cartesian coordinates in space. Retrieved from: ttp: //zno.academia.in.ua/ mod/ book / view.php? Id = 3217 (Accessed: 10.12.2020).

Стаття прийнята

до друку: 28.12.2020 p.

\section{Бібліографічний опис для цитування :}

Заблодська I. В. Декартова система координат як інструмент позиціонування об'єднаних територіальних громад України / I. В. Заблодська, К. І. Сєрєбряк, Л. І. Бєлоусова

// Часопис економічних реформ. - 2020. - № 4 (40). - С. 30-37. 